\title{
Copper Reactivity can be Tuned to Catalyse the Stereoselective Synthesis of 2-deoxy Glycosides from Glycals
}

\author{
Carlos Palo-Nieto ${ }^{a \pi}$, Abhijit Sau ${ }^{a \pi}$, Robin Jeanneret ${ }^{a}$, Pierre-Adrien Payard, ${ }^{b}$ Maristela Braga Martins- \\ Teixeira ${ }^{c}$, Ivone Carvalho ${ }^{c}$, Laurence Grimaud ${ }^{b, *}$ and M. Carmen Galan ${ }^{a *}$
}

[a] School of Chemistry, University of Bristol, Cantock's Close, BS8 3TS (UK)

[b] Laboratoire des biomolécules (LBM), Sorbonne Université - Ecole Normale Supérieure - CNRS, 24 rue Lhomond, 75005, Paris, France.

[c] School of Pharmaceutical Sciences of Ribeirão Preto, University of São Paulo, Av do Café s/n, Monte Alegre, CEP 14040-903

T.equal contribution

*Corresponding authors: Laurence.grimaud@ens.fr and M.C.Galan@bristol.ac.uk

\begin{abstract}
We demonstrate that tuning the reactivity of $\mathrm{Cu}$ by the choice of oxidation state and counterion leads to the activation of both "armed" and "disarmed" type glycals towards direct glycosylation leading to the $\alpha$-stereoselective synthesis of deoxyglycosides in good to excellent yields. Mechanistic studies show that $\mathrm{Cu}^{\prime}$ is essential for effective catalysis and stereocontrol and that the reaction proceeds through dual activation of both the enol ether as well as the $\mathrm{OH}$ nucleophile.
\end{abstract}

Carbohydrates play significant roles in a wide range of biological events. $^{[1]}$ The chemical synthesis of structurally defined oligosaccharide sequences is needed to further our understanding of their various roles and functions in health and disease and for the development on novel carbohydrate-based drugs and vaccines. ${ }^{[2]}$ Efficient catalytic and asymmetric methods to access this class of ubiquitous chiral molecules are therefore highly desirable in organic synthesis.

First row transition metals have recently attracted attention as alternatives to precious metals in catalysis. ${ }^{[3]}$ Among those, copper is a cost-effective, earth-abundant and sustainable metal and $\mathrm{Cu}$-complexes can display unique and versatile reactivity and good functional group tolerance. ${ }^{[3]}$ The chemistry exhibited by $\mathrm{Cu}$ can be very diverse depending on its oxidation state, as this metal can efficiently catalyse reactions involving one or two-electron mechanisms. ${ }^{[3-4]}$ Copper can coordinate easily to both heteroatoms and $\pi$-bonds and is known to activate terminal

[a] Dr. C. Palo-Nieto", Dr A. Sau ${ }^{\pi}$, Dr. R. Jeanneret and Prof. M. C Galan*. "equal contribution

School of Chemistry, University of Bristol, Cantock's Close, BS8 3TS (UK)

E-mail: M.C.Galan@bristol.ac.uk

[b] Mr P. A. Payard and Dr. L. Grimaud

Laboratoire des biomolécules (LBM), Sorbonne Université - Ecole

Normale Supérieure - CNRS, 24 rue Lhomond, 75005, Paris,

France.

E-mail: Laurence.grimaud@ens.fr

[c] Dr. M. Martins-Teixeira and Prof. I. Carvalho

School of Pharmaceutical Sciences of Ribeirão Preto, University of São Paulo, Av do Café s/n, Monte Alegre, CEP 14040-903

Supporting information for this article is given via a link at the end of the document. alkynes and alkenes or to catalyse the asymmetric conjugate addition of nucleophiles to electron-deficient alkenes. ${ }^{[5]}$ In the context of O-linked glycosylation reactions, a few examples of $\mathrm{Cu}$ (II) as a mild oxophilic Lewis acid catalyst for the activation of oxygen-containing leaving groups have been reported. ${ }^{[6]}$ More recently, the use of $\mathrm{Cu}^{\prime \prime}(\mathrm{OTf})_{2}$ as an in situ oxidant in the photoinduced-activation of thioglycosides was also exemplified. ${ }^{[7]}$ However, despite copper catalysts being relatively cheap and widely available, we were surprised by the overall under exploration of this metal in glycosylation chemistry ${ }^{[8]}$.

Our group is interested in the development of sustainable, practical and catalytic methods for the synthesis of oligosaccharides. ${ }^{[9]}$ In particular, 2-deoxy-hexoses are prominent components of natural products which due to the lack of substituents at $C-2$ to direct the nucleophile approach present significant synthetic challenges. This has piqued the interest of researchers to develop improved and stereoselective protocols for their assembly. ${ }^{[4,9 a, 10]}$
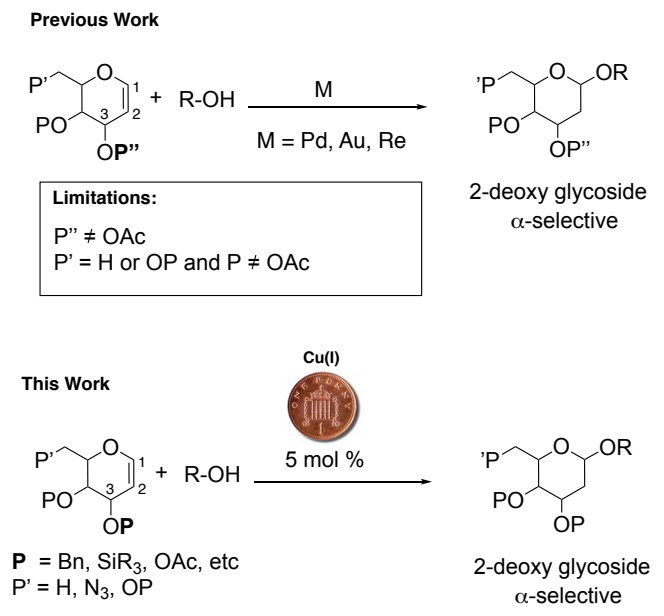

Scheme 1: Cu'-catalysed direct synthesis of deoxyglycosides from glycals

Herein we describe an unprecedented $\mathrm{Cu}^{\prime}$-catalyzed direct and stereoselective activation of cyclic enol ethers to yield 2deoxyglycosides. We demonstrate that (Cu'OTf) ${ }_{2} \mathrm{C}_{6} \mathrm{H}_{6}$ can activate both "armed" and "disarmed" type glycals to give 2deoxyglycoside products with high $\alpha$-stereocontrol. Mechanistic 
studies show that $\mathrm{Cu}(\mathrm{I})$ participates in the reaction and is essential to achieve efficient catalytic stereocontrol.

Previous work from our group and others has shown that activation of glycals to yield glycosides can be achieved using transition metals such as $\mathrm{Pd}(\mathrm{II})^{[11]}, \mathrm{Au}(\mathrm{I})^{[12]}$ or $\operatorname{Re}(\mathrm{V})^{[13]}$ catalysts, however activation of sensitive enol ethers bearing electronwithdrawing groups at the $C-3$ position of the glycal was not possible under those conditions (Scheme 1) and in general harsher reagents used to activate such glycals often lead to donor hydrolysis and/or Ferrier type products. ${ }^{[10 e]}$

Table 1. Initial catalyst screen in the glycosylation of galactal 1 a.

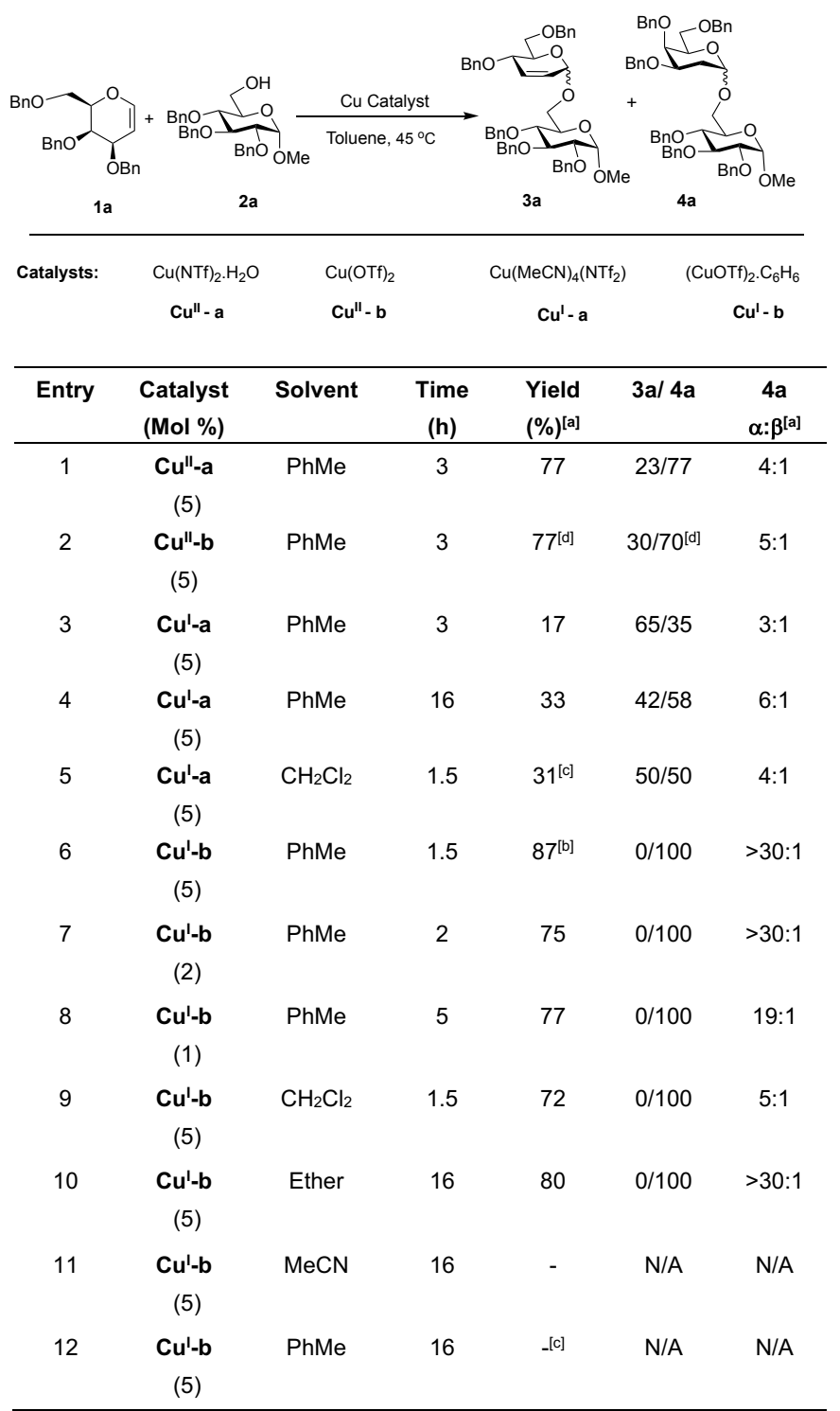

[a] Determined by ${ }^{1} \mathrm{H}-\mathrm{NMR}$. N/A = not applicable; ${ }^{[b]}$ Isolated yield. ${ }^{[c]}$ Reaction at RT. [d] Yields ranged from $61-85 \%$ and $3 a / 4 a$ ratio from $5 / 95$ and $30 / 70$ suggesting that $\mathrm{Cu}^{\mathrm{I}}-\mathrm{b}$ led to lack of reproducibility.

These findings prompted us to explore the utility of copper in the activation of glycals to yield 2-deoxyglycosides. To that end, a series of $\mathrm{Cu}(\mathrm{I})$ and $\mathrm{Cu}(\mathrm{II})$ salts were initially screened as promoters in the glycosylation of perbenzylated galactal $\mathbf{1 a}$ and glucoside acceptor $2 \mathrm{a}^{6 \mathrm{a}}$ in toluene at $45^{\circ} \mathrm{C}$. As summarized in Table 1, reactions with $\mathrm{Cu}(\mathrm{II})$ were less efficient and gave inseparable mixtures of Ferrier-type products $\mathbf{3 a}$ and deoxyglycosides $\mathbf{4 a}$ with poor stereocontrol (entries 1 and 2). Similar outcomes were observed when $\mathrm{Cu}^{\prime}(\mathrm{MeCN})_{4}\left(\mathrm{NTf}_{2}\right)\left(\mathrm{Cu}^{\prime}-\mathrm{a}\right)$ was used in either toluene or dichloromethane (entries 3-5). Encouragingly, activation with $\left(\mathrm{Cu}^{\prime} \mathrm{OTf}\right)_{2} \cdot \mathrm{C}_{6} \mathrm{H}_{6}\left(\mathbf{C u}^{\prime}-\mathbf{b}\right)$ proved more efficient and the desired 2-deoxyglycoside $4 \mathbf{a}$ was obtained in $87 \%$ yield and $30: 1 \alpha: \beta$ ratio within $1.5 \mathrm{~h}$ (entry 6 ). Next, we decided to explore the effect of catalyst loading in the model reaction. It was found that $5 \mathrm{~mol} \%$ was optimal with lower yields obtained at lower loadings (entries 7 and 8). Solvent and temperature effects were then evaluated, reactions carried out at RT (entry 12) or using acetonitrile as solvent did not proceed (entry 11), while lower yield and stereocontrol was observed in $\mathrm{CH}_{2} \mathrm{Cl}_{2}$ (entry 9). Glycosylations in diethylether afforded similar yields and stereocontrol ( $80 \%$ and $30: 1 \alpha: \beta$ ratio) albeit reactions took $18 \mathrm{~h}$ when compared to toluene (entry 10 vs 6 ).

Table 2. Reaction of glycal $\mathbf{1 a}$ with glycoside acceptors $\mathbf{2 b - 2 i}$.

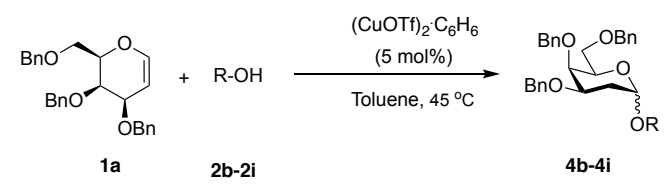

\begin{tabular}{llllll}
\hline Entry & $\mathbf{2 b}$ & $\begin{array}{c}\text { Time } \\
\mathbf{( h )}\end{array}$ & $\begin{array}{c}\text { Yield } \\
(\mathbf{\%})^{[\mathbf{a}]}\end{array}$ & $\boldsymbol{\alpha}: \boldsymbol{\beta}^{[\mathbf{b}]}$ \\
\hline 1 & & & & \\
\hline
\end{tabular}

[a] Isolated yield. ${ }^{[b]}$ Determined by ${ }^{1} \mathrm{H}-N M R$. ${ }^{[c]}$ Reaction did not proceed in the absence of catalyst. [d] Reaction using $\mathrm{Cu}(\mathrm{II})(\mathrm{OTf})_{2}(5 \mathrm{~mol} \%)$ and sodium ascorbate $(10 \mathrm{~mol} \%)$ to generate $\mathrm{Cu}(\mathrm{I})$ in situ also afforded $4 \mathrm{c}$ in $89 \%$ yield and $>30: 1 \alpha: \beta$.

Having established the optimum reaction conditions, the substrate scope of the glycosylation was thus investigated. Galactal 1a was reacted with a range of primary and secondary 
$\mathrm{OH}$ nucleophiles $\mathbf{2} \mathbf{b}-\mathbf{2} \mathbf{i}^{[14]}$ under the optimized reaction conditions (Table 2). In all cases, reactions proceeded smoothly and in good to excellent yields and $\alpha$-selectivity, demonstrating that the catalytic system tolerates the presence of common alcohol and amine protecting groups such as acetals, ethers, esters and carbamates. Glycosylations with primary alcohols such as simple benzyl alcohol $\mathbf{2 b}$, glycosides $\mathbf{2 c}$ and $\mathbf{2 d}$, thioglycoside $\mathbf{2 e}$ and Boc-protected serine $2 \mathrm{f}$ afforded the corresponding glycoside products in $79-88 \%$ yield within $2 \mathrm{~h}$ and with an $>30: 1 \alpha: \beta$ ratio (Table 2, entries 1-5). Similarly, reactions with secondary alcohols such as, glycoside $\mathbf{2 g}$, Boc-protected threonine $\mathbf{2 h}$ and cholesterol $\mathbf{2} \mathbf{i}$ also afforded the desired products in good yields $(72-75 \%)$ and with high $\alpha$-selectivity $(>30: 1 \quad \alpha: \beta$ ratio, entries 6 8).

Next, the scope of the reaction with respect to the glycal donor was investigated. To that end, a series of differentially protected galactals $\mathbf{1 b}-\mathbf{1 h}$, glucals $5 \mathrm{a}$ and $\mathbf{5 b}$ and fucal $\mathbf{6}$ bearing benzyl, acetate, methoxymethyl acetal, silyl ether and siloxane protecting groups were prepared and subjected to the glycosylation conditions with $\mathbf{2 a}$ or $\mathbf{2} \mathbf{g}$ as the acceptors (Table 3 ). Pleasingly, reactions involving galactal donors $1 \mathrm{c}-1 \mathrm{~h}$ were complete within $2-4 \mathrm{~h}$ and in yields of $72-98 \%$ and high $\alpha$-selectivities (15:1 to $30: 1$ ) (entries 2-6). Excitingly, Cu'-activation of galactals bearing acetyl groups at $\mathrm{C}-3$ such peracetylated galactal $\mathbf{1 b}$ and silyl acetal $\mathbf{1 h}$ with $\mathbf{2 a}$ gave glycosylation products $\mathbf{7 b}$ and $\mathbf{7 h}$, in $63 \%$ and $84 \%$ yield respectively, with high $\alpha$-stereocontrol (entries 1 and 7). This is noteworthy, as most protocols used to activate 'disarmed' glycals tend to give mixtures of glycoside and Ferriertype products $\left.{ }^{[9 a}, 9 b, 11 b\right]$ as we also observe when using $\mathrm{Cu}(\mathrm{II})(67-$ $79 \%$ of anomeric mixtures of Ferrier and 2-deoxy glycoside products 13:87-25:75; Table 3 , entry $1^{[\mathrm{d}]}$ ). The reaction was also amenable to glycosylations with glucal substrates, and reactions with 3,4-O-siloxane-protected $\mathbf{5 a}^{[15]}$ or $\mathbf{5}^{[15]}$ afforded the corresponding glycosides $\mathbf{8 a}, \mathbf{8 b}$ and $\mathbf{9}$ in high $\alpha$-stereocontrol $(>30: 1 \alpha: \beta)$ and yields (72-79\%) within 1-4 $\mathrm{h}$ (entries 8-10). Under the Cu-catalysed reaction, peracetylated glucal $5 \mathrm{c}$ could also be activated, however it afforded Ferrier type glycoside 10 as the major product $(67 \%, 78: 22 \alpha: \beta$, entry 11$)$, as expected for glucal substrates bearing an acetate at $\mathrm{C}-3 .^{[11 \mathrm{~b}]}$ Moreover, activation of peracetylated L-fucal $\mathbf{6}^{[9 \mathrm{a}]}$ afforded 2,6dideoxyglycoside $\mathbf{1 0}$ in $71 \%$ yield within $2 \mathrm{~h}$ and in a >30:1 $\alpha: \beta$ ratio (entry 12).

To probe the mechanism of our reaction, a $3: 1 \alpha / \beta$-anomeric disaccharide mixture (4j, see ESI for details) was subjected to the reaction conditions in the absence and presence of the $\mathrm{OH}$ acceptor and gave no change in the anomeric ratio, indicating that the high a-selectivity is not the result of anomerization (Fig S2 in ESI). Reaction with deuterated galactal 10 yielded disaccharides $11 \mathrm{a}$ and $11 \mathrm{~b}$ in $70 \%$ yield as a $2: 1$ mixture of cis:trans products in favor of equatorial protonation and axial addition of the $\mathrm{OH}$ nucleophile across the double bond, suggesting that initial alkene activation has very little directing influence on the anomeric selectivity (Scheme 2). In the presence of $20 \mathrm{~mol} \%$ of DIPEA the reaction between galactal $\mathbf{1 a}$ and $\mathbf{2 d}$ using either $\mathbf{C u}^{\prime}-\mathbf{b}$ or $\mathbf{C} \mathbf{u}^{\prime \prime}-\mathbf{b}$ was inhibited, which suggests that the presence of brösted acid might be involved in the reaction mechanism. ${ }^{\left[{ }^{[c]}\right]}$ To evaluate this, reactions between both $1 \mathrm{a}$ and $\mathbf{1 b}$ and $\mathbf{2 a}$ in the presence of $0.1-2 \mathrm{~mol} \%$ of $\mathrm{TfOH}$ were carried out in toluene (Table S1 in ESI). In general, lower conversions $(20-60 \%)$ and selectivities $(3: 1 \alpha: \beta$ ratios) were observed in all cases and inseparable mixtures of glycoside products and other by-products were obtained (see ESI for details). This suggests that although a catalytic amount of $\mathrm{TfOH}$ alone is able to activate both armed and disarmed glycals, $\mathrm{Cu}(\mathrm{I})$ is essential for effective and controlled catalysis.

\section{Table 3. Reaction of glycals $\mathbf{1 b}-\mathbf{1 h}, \mathbf{5 a}, \mathbf{5 b}$ and $\mathbf{8}$ with acceptors $\mathbf{2 a}$ or $\mathbf{2 g}$.}

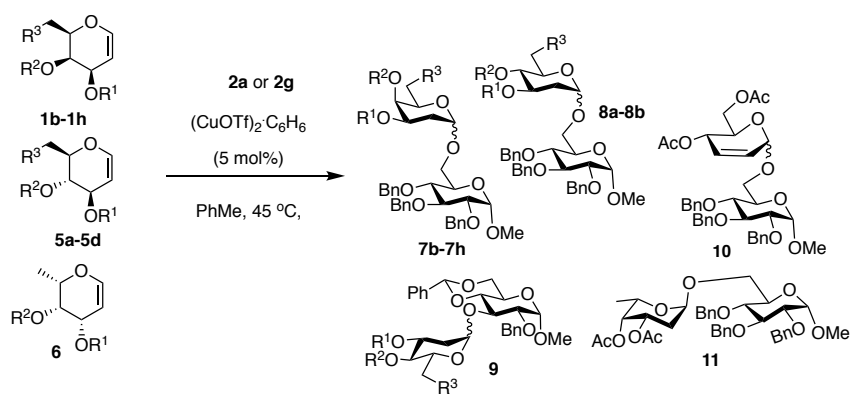

\begin{tabular}{|c|c|c|c|c|c|c|c|c|}
\hline Entry & Donor & R1 & R2 & R3 & Product & $\begin{array}{c}\text { Time } \\
\text { (h) }\end{array}$ & $\begin{array}{l}\text { Yield } \\
(\%)^{[a]}\end{array}$ & $\alpha: \beta^{[b]}$ \\
\hline 1 & $1 b$ & $A c$ & $A c$ & OAc & $7 b$ & 2 & $63^{[c][d]}$ & $15: 1$ \\
\hline 2 & $1 c$ & $\mathrm{Bn}$ & $\mathrm{Bn}$ & OAC & $7 c$ & 3 & 80 & $25: 1$ \\
\hline 3 & $1 d$ & TBS & TBS & OTBS & $7 d$ & 4 & 78 & $30: 1$ \\
\hline 4 & $1 e$ & TBS & TBS & $\mathrm{N}_{3}$ & $7 e$ & 4 & 98 & $30: 1$ \\
\hline 5 & $1 f$ & MOM & MOM & OMOM & $7 f$ & 3 & 75 & $30: 1$ \\
\hline 6 & $1 \mathrm{~g}$ & MOM & \multicolumn{2}{|c|}{$\mathrm{OSi}(t B u)_{2}$} & $7 \mathrm{~g}$ & 3 & 72 & $30: 1$ \\
\hline 7 & $1 \mathrm{~h}$ & $A c$ & \multicolumn{2}{|c|}{$\mathrm{OSi}(t B u)_{2}$} & $7 \mathrm{~h}$ & 3 & 84 & $21: 1$ \\
\hline 8 & $5 a$ & \multicolumn{2}{|c|}{$\mathrm{O}\left[\mathrm{Si}(i \mathrm{Pr})_{2}\right]_{2}$} & OTIPS & $8 a$ & 3 & $72^{[c]}$ & $30: 1$ \\
\hline 9 & $5 b$ & \multicolumn{2}{|c|}{$\mathrm{O}\left[\mathrm{Si}(i \mathrm{Pr})_{2}\right]_{2}$} & OBn & $8 b$ & 4 & $79^{[c]}$ & $30: 1$ \\
\hline 10 & $5 b$ & \multicolumn{2}{|c|}{$\mathrm{O}\left[\mathrm{Si}(\mathrm{iPr})_{2}\right]_{2}$} & OBn & 9 & 1 & $75^{[\mathrm{c}]}$ & $30: 1$ \\
\hline 11 & $5 c$ & $A c$ & $A c$ & OAc & 10 & 5 & $67^{[d]}$ & $78: 22$ \\
\hline 12 & 6 & $A c$ & $\mathrm{Ac}$ & - & 11 & 2 & $71^{[c]}$ & $30: 1$ \\
\hline
\end{tabular}

${ }^{[a]}$ Isolated yield. ${ }^{[b]}$ Determined by ${ }^{1} \mathrm{H}-N M R .{ }^{[c]}$ Reaction was carried out at $70^{\circ} \mathrm{C}$. ${ }^{[\mathrm{d}]}$ reactions using $\mathbf{C u}^{\text {II-a }}$ or $\mathbf{C u}^{\text {"l-}}$-b afforded inseparable anomeric mixtures of Ferrier and glycoside products $\left(13: 87(79 \%)\right.$ and $25: 75(67 \%)$, respectively). ${ }^{[d]}$ The reaction favoured the Ferrier product over the 2-deoxyglycoside product (15\%)).

Scheme 2. Glycosylation of deuterated glycal donor 12 with $\mathbf{2 a}$.

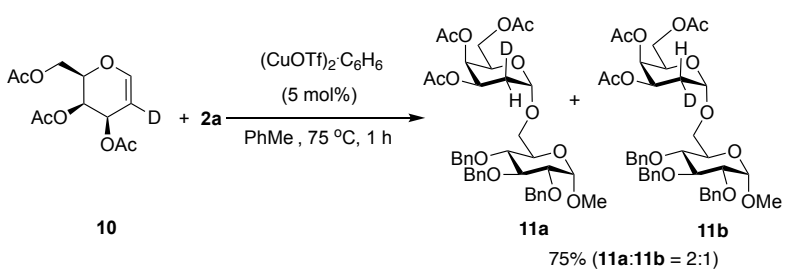

${ }^{1} \mathrm{H}-\mathrm{NMR}$ spectroscopy studies carried out at room temperature in toluene- $\mathrm{d}^{8}$ of equimolar mixtures of $\mathrm{Cu}(\mathrm{I})$ catalyst and glycoside acceptor $\mathbf{2 a}$ showed signal broadening for $\mathbf{2 a}$, suggesting an interaction between $\mathrm{Cu}(\mathrm{I})$ and the alcohol (Fig. S3). NMR mixtures of 1 eq. (Cu'OTf) ${ }_{2} \cdot \mathrm{C}_{6} \mathrm{H}_{6}$ and galactal 1 a also showed slight $\mathrm{H}$ shifts and peak broadening associated with an interaction between the alkene protons in $1 \mathbf{a}$ (from $\delta 6.22$ to $6.21 \mathrm{ppm}$ ), while mixtures of 1 eq. Cu"(OTf) $)_{2}$ and 1 a led to quick glycal activation and formation of degradation products (See Figs. S4-S6 in ESI). 
On the other hand, no interactions between deactivated peracetylated galactal $\mathbf{1 b}$ and $\mathrm{Cu}(\mathrm{I})$ were observed by ${ }^{1} \mathrm{H}-\mathrm{NMR}$ at room temperature, while slow degradation of $\mathbf{1} \mathbf{b}$ in the presence of $\mathrm{Cu}(\mathrm{II}) \mathrm{OTf}_{2}$ could be seen over time (Fig. S7 and S8). Moreover, reaction between $1 \mathrm{a}$ and $\mathbf{2 c}$ using $5 \mathrm{~mol} \% \mathrm{Cu}^{\prime \prime}(\mathrm{OTf})_{2}$ and $10 \mathrm{~mol} \%$ sodium ascorbate (to generate $\mathrm{Cu}(\mathrm{I})$ in situ) also afforded $4 \mathrm{c}$ in $89 \%$ yield and $>30: 1 \alpha: \beta$ (Table 2 , entry $2^{[\mathrm{dd}]}$ ). This result further indicates that $\mathrm{Cu}(\mathrm{I})$ is important for effective catalysis towards stereoselectvie glycosylation and stereocontrol.
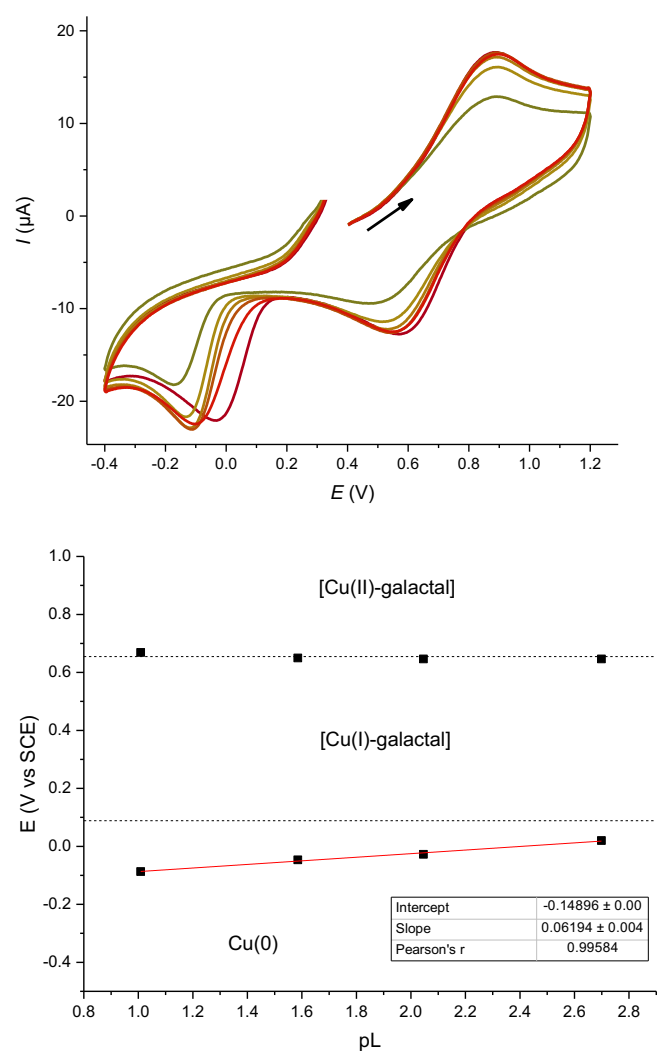

Figure 1. top: $\mathrm{CV}$ towards oxidation potentials of [Cu'(OTf)] (2 mM) in the presence of benzyl alcohol (158 equiv) with increasing amounts of tri-acetylgalactal, recorded at a steady glassy carbon disk electrode $(\mathrm{d}=3 \mathrm{~mm})$ in nitromethane containing $n-\mathrm{Bu}_{4} \mathrm{NBF}_{4}(0.3 \mathrm{M})$ at $20^{\circ} \mathrm{C}$ with a scan rate of $0.5 \mathrm{~V} \mathrm{~s}$ ${ }^{1}$. $(0,1,2,5,14,50$ equiv). bottom: Potential-pL $(\mathrm{L}=$ tri-acetyl-galactal, $\mathrm{pL}=$ $\log (L))$ plot constructed using the $E(1 / 2)$ values extracted from the CV plots in the presence of excess $\mathrm{BnOH}$ (158 equiv). SCE = saturated calomel Electrode.

To better understand the interactions between the $\mathrm{Cu}$ catalysts and both donor $\mathbf{1 b}$ and $\mathrm{OH}$ nucleophile, cyclic voltammetry experiments were undertaken. The electrochemical behaviors of both $\mathrm{Cu}^{\prime \prime}\left(\mathrm{NTf}_{2}\right)_{2}$ and $\left[\mathrm{Cu}^{\prime}(\mathrm{OTf})\right]_{2}$ were studied in nitromethane (Figure 1, $\left[\mathrm{Cu}^{\prime}(\mathrm{OTf})\right]_{2}$ data shown). The use of a poorly coordinating solvent such as nitromethane allowed us to investigate the interaction of both $\mathrm{Cu}(\mathrm{II})$ and $\mathrm{Cu}(\mathrm{I})$ with a ligand, while neutral ligands triflimide or triflate anions were used indistinctly (as they exhibited the same electrochemical behaviour in this instance) to avoid any binding competition issues. The reduction of $\mathrm{Cu}(\mathrm{II})$ to $\mathrm{Cu}(\mathrm{I})$ is a reversible transfer occurring around $E_{1 / 2}=+0.8 \mathrm{~V}$ vs SCE, while the electrodeposition and oxidative dissolution of $\mathrm{Cu}(0)$ occurred at $+0.1 \mathrm{~V}$ and $+0.6 \mathrm{~V}$, respectively. Cyclohexene was first chosen as a model ligand to mimic the interaction between $\mathrm{Cu}(\mathrm{II})$ or $\mathrm{Cu}(\mathrm{I})$ and a carbon-carbon double bond. In the presence of cyclohexene, the reduction peak of $\mathrm{Cu}$ (II) was shifted towards higher potentials, while the reduction peak of $\mathrm{Cu}(\mathrm{I})$ was shifted towards lower potentials (Figure S9). The evolution of these reduction potentials was studied with increasing amounts of alkene. The results proved a stabilization of $\mathrm{Cu}(\mathrm{I})$ by the alkene due to the formation of a $1: 1$ complex between $\mathrm{Cu}(\mathrm{I})$ and cyclohexene, as previously reported. ${ }^{[17]}$ On the other hand, cyclohexene has no interaction with $\mathrm{Cu}$ (II) (see Figure $\mathrm{S} 12$ in $\mathrm{ESI}$ ).

The interaction of $\mathrm{Cu}(\mathrm{II})$ and $\mathrm{Cu}(\mathrm{I})$ with tri-acetyl galactal $\mathbf{1 b}$ was next considered (see Supporting Information, Figure S13), since previous reported methods failed to activate electron-poor glycals towards direct glycosylation ${ }^{[9 a, 9 b, 11 b]}$ and we wanted to better understand the interaction with the metal. In the presence of $1 \mathbf{b}$, the reduction peaks of both $\mathrm{Cu}(\mathrm{I})$ and $\mathrm{Cu}(\mathrm{II})$ were shifted towards lower potentials, respectively. These observations are consistent with the formation of different Cu-galactal complexes between $\mathrm{Cu}(\mathrm{I})$ and tri-acetyl galactal $\mathbf{1 b}$ and also between $\mathrm{Cu}(\mathrm{II})$ and $\mathbf{1 b}$. The latter is likely the result from an interaction between $\mathrm{Cu}(\mathrm{II})$ and acetates as expected from its oxophilic Lewis acid nature and also since no interaction with carbon-carbon double bond was observed in the experiment on cyclohexene. However, the $\mathrm{Cu}(\mathrm{I})$-galactal complex has a lower stoichiometry than the $\mathrm{Cu}(\mathrm{I})$-cyclohexene one, in agreement with the formation of aggregates (see ESI Figure S14).

The interaction between the $\mathrm{OH}$ nucleophile and copper was also studied and $\mathrm{BnOH}$ was chosen as a model substrate, as it was the simplest alcohol used in our scope. In the presence of $\mathrm{BnOH}$, the reduction peak of $\mathrm{Cu}(\mathrm{II})$ was shifted towards lower potentials, as was the reduction peak of $\mathrm{Cu}(\mathrm{I})$ (See Supporting Information, Figure S15). These observations are consistent with the formation of complexes between $\mathrm{BnOH}$ and both $\mathrm{Cu}(\mathrm{I})$ and $\mathrm{Cu}(\mathrm{II})$ with a higher stoichiometry for the $\mathrm{Cu}(\mathrm{II})$ complex (see Supporting Information, Figure S16).

Finally, in order to study the nature of the catalyst under conditions close to the catalytic ones, increasing amounts of

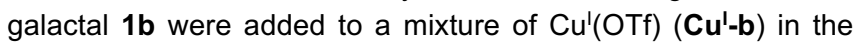
presence of an excess of $\mathrm{BnOH}$ (158 equiv). ${ }^{[18]}$ The reduction peak of $\mathrm{Cu}(\mathrm{l})$ was shifted towards lower potentials (Figure 1 and Figure S19). This is consistent with the formation of a complex between $\mathrm{Cu}(\mathrm{I})$ and $\mathbf{1} \mathbf{b}$ even in the presence of a large excess of $\mathrm{BnOH}$.

The shifts of both reduction and oxidation peaks associated with the $\mathrm{Cu}(\mathrm{II})$ and $\mathrm{Cu}(\mathrm{I})$ redox couple measured are not trivial, but the addition of galactal seems to poorly impact them, which is consistent with the formation of a $\mathrm{Cu}(\mathrm{II})-\mathbf{1 b}$ complex of stoichiometry similar to that of the $\mathrm{Cu}(\mathrm{I})-1 \mathrm{~b}$ complex. The slope of the $E$ vs pL plot for the potential associated to $\mathrm{Cu}(\mathrm{I}) / \mathrm{Cu}(0)$ is close to 0.06 (Figure 2), indicating a 1:1 stoichiometry for $\mathrm{Cu}(\mathrm{I})$ and $\mathbf{1 b}$. When comparing with the slope observed in the absence of $\mathrm{BnOH}(0.02$, Figure S14) it appears that $\mathrm{BnOH}$ is able to dissociate the metallic clusters formed between $\mathrm{Cu}(\mathrm{I})$ and $\mathbf{1} \mathbf{b}$. Indeed, the slope associated to $\mathrm{Cu}(\mathrm{II}) / \mathrm{Cu}(\mathrm{I})$ is close to 0 indicating that the complexes formed between $\mathrm{Cu}(\mathrm{II})$ and $\mathbf{1 b}$ also have a 1:1 stoichiometry (as observed in the absence of $\mathrm{BnOH}$ ). 


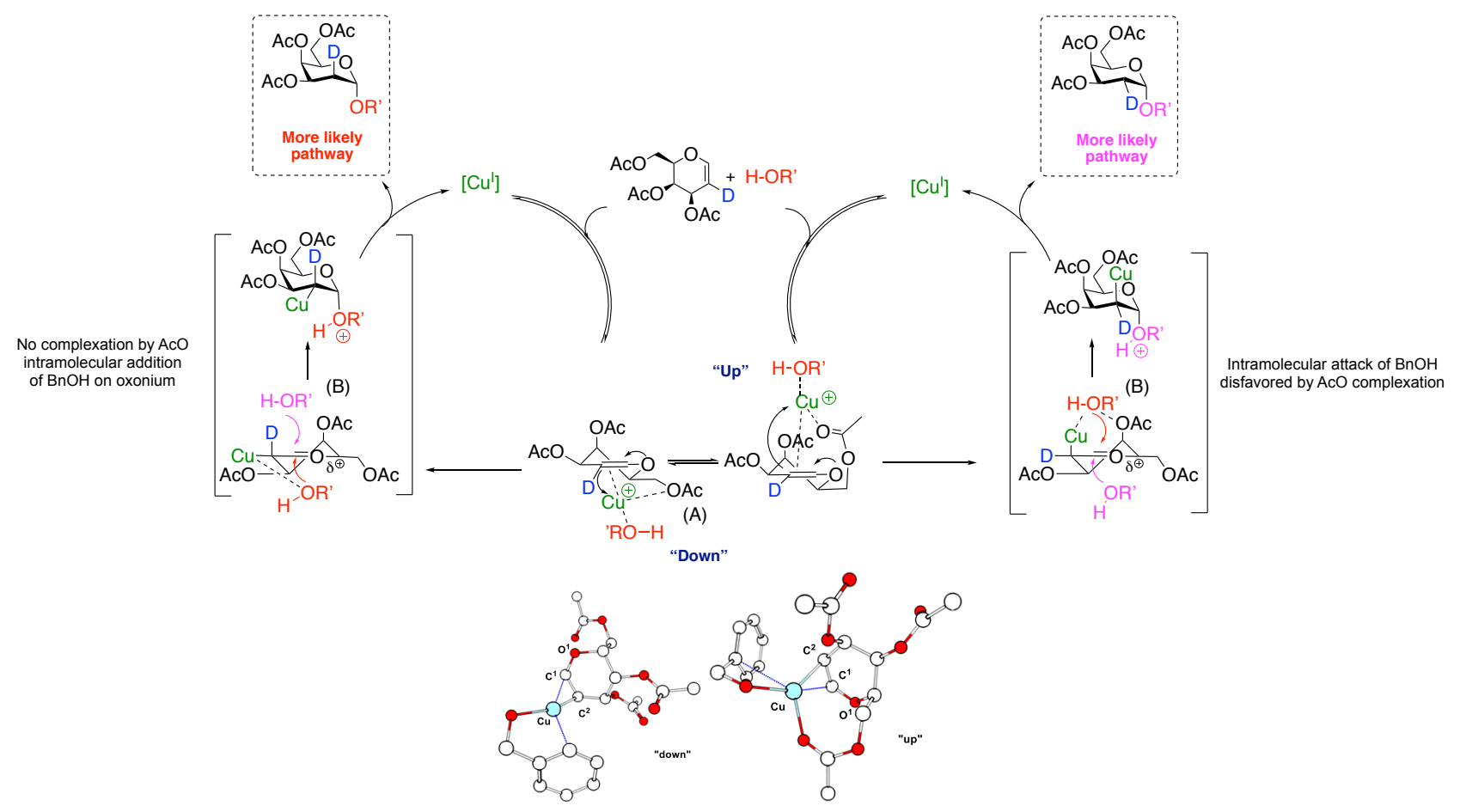

Scheme 3. Proposed mechanism and 3D structures of mixed complexes [Cu(tri-acetyl galactal $1 \mathrm{~b})(\mathrm{ROH})]^{+}$optimized at the DFT B3LYP/def2-SVP level.

From our mechanistic studies one can conclude that (i) $\mathrm{Cu}(\mathrm{I}) \mathrm{OTf}$ leads to activation of the carbon-carbon double bond of glycals and that in the case of electron-deficient enol ethers, $\mathrm{Cu}(\mathrm{I})$-interactions with the acyl groups facilitate the activation of the "disarmed" glycal; ${ }^{[19]}$ (ii) the active form of the catalyst is likely a complex involving both the glycal and the $\mathrm{OH}$ nucleophile $[\mathrm{Cu}(\mathrm{Glycal})(\mathrm{ROH})]^{+}$.

Two possible isomers of $[\mathrm{Cu}(\text { Glycal } \mathbf{1 b})(\mathrm{ROH})]^{+}$were optimized using DFT at the B3LYP/def2-SVP level to help us provide some insights with regards to the active species (see the SI for computational details): one featuring a copper-acetate interaction ("up") and one with the copper in the position opposite to the acetate moieties ("down"). Upon coordination to the $\mathrm{C}=\mathrm{C}$ bond, copper induces a modification of the electronic structure (Figure S20 and Table S1, ESI). The electronic density on the carbon $C^{2}$ increases (-0.063 for up and -0.161 for down) while the one on $\mathrm{O}^{1}$ and $\mathrm{C}^{1}$ ( +0.075 for up and +0.104 for down) decreases. In the meantime, the $\mathrm{C}=\mathrm{C}$ bond length increases $(+0.032$ for up and +0.040 for down) while the $\mathrm{C}=\mathrm{O}$ bond shortens $(-0.008$ for up and -0.019 for down). All these observations suggest that these complexes have a carbocation-like behaviour, which it is even more important for the "down" complex.

Based on these observations, a mechanism can be proposed involving two $[\mathrm{Cu}(\mathrm{Glycal})(\mathrm{ROH})]^{+}$complexes "up" or "down" (A) which can form two different oxocarbenium intermediates $(B)$ that are quickly trapped by the $\mathrm{OH}$ nucleophile to yield the glycoside products (Scheme 3 ). Two alternative pathways can be invoked for the nucleophile addition, one involving an outer sphere attack of the $\mathrm{OH}$ nucleophile (not coordinated to $\mathrm{Cu}$ ) on the carbocation ((B) pink arrows) and a second one with an inner sphere addition involving the $\mathrm{ROH}$ coordinated to $\mathrm{Cu}((\mathrm{B})$ red arrows). Based on the labelling experiments (Scheme 2 ), it seems that a bottom face attack of the nucleophile is preferred.
In summary, we have shown that adjusting the oxidation state and counter ion of $\mathrm{Cu}$ can be exploited to control the reactivity profile of these catalysts. We demonstrate for the first time the $\mathrm{Cu}^{\prime}$-catalyzed direct $\alpha$-stereoselective glycosylation of glycals to give 2-deoxyglycosides in high yields and $\alpha$ stereocontrol. The reaction is tolerant of most common protecting groups in both the glycal donor and nucleophile acceptor, including electron-deficient enol ethers which could not be activated by other mild methods to selectively yield 2-deoxy glycoside products. ${ }^{[10 \mathrm{e}]}$ It also presents a mechanistically uncommon/interesting example of Cu-catalyzed enol ether activation/functionalization. Both experimental tests and theoretical analysis indicate that the reaction may proceed through dual activation of both the enol ether as well as the nucleophile, whereby the Cu catalyst plays a key role in effective glycosylation and stereocontrol. Understanding the reactivity of these type of catalytic systems is of fundamental importance to be able to exploit the repertoire of transition metal catalysis in synthesis.

\section{Acknowledgements}

MCG, RJ and AS thank the European Research Council (ERCCOG: 648239) and CPN thanks RS Newton Fellowship. LG thanks the CNRS, the ENS/PSL and the ENS Paris Saclay (Ph.D. scholarship to P.-A.P.) for financial support. IC and MBMT thank Fundação de Amparo à Pesquisa do Estado de São Paulo FAPESP Proc n. 2016/21194-6

Keywords: Stereoselectivity - Copper catalysis • Glycosylation • Enol ether • Glycals 


\section{References}

[1] A. Varki, Glycobiology 2014, 24, 1086-1087.

[2] a) M. C. Galan, D. Benito-Alifonso, G. M. Watt, Org. Biomol. Chem. 2011, 9, 3598-3610; b) M. C. Galan, P. Dumy, O. Renaudet, Chem. Soc. Rev. 2013, 42, 4599-4612.

[3] X. Zhu, S. Chiba, Chem. Soc. Rev. 2016, 45, 4504-4523.

[4] J. M. Nogueira, M. Bylsma, D. K. Bright, C. S. Bennett, Angew. Chem. Int. Ed. 2016, 55, 10088-10092.

[5] a) S. R. Chemler, Beilstein J. Org. Chem. 2015, 11, 2252-2253; b) T. E. Schmid, S. Drissi-Amraoui, C. Crevisy, O. Basle, M. Mauduit, Beilstein J. Org. Chem. 2015, 11, 2418-2434.

[6] a) S. Sato, M. Mori, Y. Ito, T. Ogawa, Carbohydr. Res. 1986, 155, C6C10; b) H. Yamada, T. Hayashi, Carbohydr. Res. 2002, 337, 581-585; c) A. K. Kusunuru, M. Tatina, S. K. Yousuf, D. Mukherjee, Chem Commun 2013, 49, 10154-10156. (C-glycosides); d) R. Joseph, F. B. Dyer, P. Garner, Org Lett 2013, 15, 732-735 (N-glycopeptides). e) B. Srinivas, T. R. Reddy, P. R. Krishna, S. Kashyap, Synlett 2014, 25, 1325-1330; f) S. K. Battina, S. Kashyap, Tetrahedron Lett. 2016, 57, 811-814; g) T. Verdelet; S. Benmahdjoub; B. Benmerad; M. Alami; S. Messaoudi, J. Org. Chem. 2019, 84, 9226-9238.

[7] R. Z. Mao, F. Guo, D. C. Xiong, Q. Li, J. Y. Duan, X. S. Ye, Org. Lett. 2015, 17, 5606-5609.

[8] a) X. H. Li, J. L. Zhu, J. Carbohydr. Chem. 2012, 31, 284-324; b) X. H. Li, J. L. Zhu, Eur. J. Org. Chem. 2016, 4724-4767; c) E. T. Sletten, Y. J. Tu, H. B. Schlegel, H. M. Nguyen, ACS Catal. 2019, 9, 2110-2123; d) M. J. McKay, H. M. Nguyen, ACS Catal. 2012, 2, 1563-1595; e) J. Ling, C. S. Bennett, Asian J. Org. Chem. 2019, 8, 802-813.

[9] a) A. Sau, C. Palo-Nieto, M. C. Galan, J. Org. Chem. 2019, 5, 2415-2424; b) C. Palo-Nieto, A. Sau, R. Williams, M. C. Galan, J. Org. Chem. 2017, 82, 407-414; c) R. J. Beattie, T. W. Hornsby, G. Craig, M. C. Galan, C. L. Willis, Chem. Sci. 2016, 7, 2743-2747; d) S. Medina, A. S. Henderson, J. F. Bower, M. C. Galan, Chem. Commun. 2015, 51, 8939-8941.

[10] a) S. Medina, M. C. Galan, Carbohydr. Chem. 2016, 41, 59-89; bD. Benito-Alifonso, G. M. C., in Selective Glycosylations: Synthetic Methods and Catalysis (Ed.: C. E. Bennett), 2017, pp. 155-171; c) R. Williams, M C. Galan, Eur. J. Org. Chem. 2017, 6247-6264; d) J. Zeng, Y. Xu, H. Wang, L. K. Meng, Q. Wan, Sci. China Chem. 2017, 60, 1162-1179; e) C. S. Bennett, M. C. Galan, Chem. Rev. 2018, 118, 7931-7985; f) T. M Beale, P. J. Moon, M. S. Taylor, Org. Lett. 2014, 16, 3604-3607; g) H. Wang, J. Y. Tao, X. P. Cai, W. Chen, Y. Q. Zhao, Y. Xu, W. Yao, J. Zeng, Q. Wan, Chem. Eur. J. 2014, 20, 17319-17323; h) D. Y. Zhu, K. N. Baryal, S. Adhikari, J. L. Zhu, J. Am. Chem. Soc. 2014, 136, 3172-3175; i) M. Kaneko, S. B. Herzon, Org. Lett. 2014, 16, 2776-2779; j) T. K. Pradhan K. K. T. Mong, Israel J. Chem. 2015, 55, 285-296; k) S. Das, D. Pekel, J. M. Neudorfl, A. Berkessel, Angew. Chem. Int. Ed. 2015, 54, 12479 12483; I) W. Z. Song, S. J. Wang, W. P. Tang, Chem. Asian J. 2017, 12, 1027-1042; m) G. Y. Zhao, T. Wang, Angew. Chem. Int. Ed. 2018, 57 6120-6124; n) S. E. Soliman, C. S. Bennett, Org. Lett. 2018, 20, 3413 3417; o) D. Lloyd, C. S. Bennett, Chem. Eur. J. 2018, 24, 7610-7614; p) G. A. Bradshaw, A. C. Colgan, N. P. Allen, I. Pongener, M. B. Boland, Y. Ortin, E. M. McGarrigle, Chem. Sci. 2019, 10, 508-514.q) K. M. Hoang, N. R. Lees, S. B. Herzon, J. Am. Chem. Soc. 2019, 141, 8098-8103

[11] a) A. Sau, R. Williams, C. Palo-Nieto, A. Franconetti, S. Medina, M. C. Galan, Angew. Chem. Int. Ed. 2017, 56, 3640-3644; b) A. Sau, M. C Galan, Org. Lett. 2017, 19, 2857-2860.

[12] C. Palo-Nieto, A. Sau, M. C. Galan, J. Am. Chem. Soc. 2017, 139, 14041 14044.

[13] B. D. Sherry, R. N. Loy, F. D. Toste, J. Am. Chem. Soc. 2004, 126, 4510 4511.

[14] E. I. Balmond, D. M. Coe, M. C. Galan, E. M. McGarrigle, Angew. Chem. Int. Ed. 2012, 51, 9152-9155.

[15] E. I. Balmond, D. Benito-Alifonso, D. M. Coe, R. W. Alder, E. M. McGarrigle, M. C. Galan, Angew. Chem. Int. Ed. 2014, 53, 8190-8194.
[16] D. Hager, P. Mayer, C. Paulitz, J. Tiebes, D. Trauner, Angew. Chem. Int Ed. 2012, 51, 6525-6528.

[17] a) R. G. Salomon, J. K. Kochi, J. Am. Chem. Soc. 1973, 95, 1889-1897; bR. G. Solomon, J. K. Kochi, J. Chem. Soc. Chem. Commun. 1972, 559\&; c) B. W. Cook, R. G. J. Miller, P. F. Todd, J Organomet. Chem. 1969, 19, 421-\&.

[18] A model competition study between $\mathrm{BnOH}$ and cyclohexene was also studied. See SI for details

[19] A parallel mechanism of glycal activation in which traces of triflic acid or another proton donor species are involved can not be completely discarded. 